\title{
CFD Evaluation of Experimental Measurements of Oscillating Mist Fan Cooling in a Large Indoor Space
}

\author{
Craig Farnham ${ }^{1}$, Jihui Yuan ${ }^{2}$, Kazuo Emura ${ }^{1}$, Md Ashraful Alam ${ }^{3}$, Takeo Mizuno \\ ${ }^{1}$ Osaka City University, Graduate School of Human Life Science, Osaka, Japan \\ ${ }^{2}$ Osaka University, Graduate School of Human Life Science, Osaka, Japan \\ ${ }^{3}$ University of Tokyo, Department of Global Health Policy, Tokyo, Japan \\ ${ }^{4}$ H. Ikeuchi \& Co. Ltd., Osaka, Japan
}

\begin{abstract}
An oscillating mist fan is a low-energy means to reduce heat stress of people in hot environments by combining evaporative and convective cooling. Mist sprays can wet sensors, yielding the wet bulb temperature rather than the true dry bulb air temperature, which is needed to model the physiological effect of cooling. This research is a study in how simulation can help reveal the true conditions in a case where sensors in experiment may not be reliable measures of reality. Simulation reveals that temperature drops may be about $1^{\circ} \mathrm{C}$ greater than recorded values.
\end{abstract}

\section{Introduction}

Thermal stress is hazardous to workers' health, yet air conditioning of large spaces such as factories can be impractical. Hydraulic mist systems spraying fine water droplets provide cooling at low energy cost. When combined with a fan, the evaporation and convection cooling effects yield can greatly increase thermal comfort (Yamada, 2006). However, if used indoors, air could quickly reach saturation.

An oscillating fan spreads the cooling effect over a wider area as well as keeping the indoor air well-mixed, promoting ventilation, while preventing local build-up of humidity and reducing the chance of undesired wetting. Measurement of the temperature changes inside and near mist are not reliable, as sensors may become wet and read near the wet bulb temperature rather than the actual dry bulb temperature. Further, the response time of many sensors is of the same magnitude or slower than the exposure time as an oscillating fan mist plume passes by. Computational fluid dynamics (CFD) simulation of the mist plume could reveal the actual temperature changes inside the mist, without the wet sensor and time-lag problems. If simulated temperatures match the reliable measured temperature beyond the mist plume where there is cooling but no wetting, and sensor time lag is accounted for, it might be assumed the simulated temperatures inside the mist plume better reflect reality than what wet sensors would yield. Knowledge of the true temperature transient over time is essential for evaluating the cooling effect both physiologically and of human thermal comfort due to thermal transients toward the comfortable state, the concept of alliesthesia (Parkinson and de Dear, 2015). Accurate prediction of the cooling effect of mist on the human body can be used to deploy systems effectively, and project reductions in the risk of heat stroke through human heat transfer models such as outlined in ISO 7933 (International Organization for Standardization, 2004).

CFD simulation can also be used to visualize the cooling effect and circulation of the air throughout the entire space. The changes in humidity can also be mapped for the entire space. Knowing the rate at which indoor humidity increases as a function of air exchanges and mist spray rate allows selection of a mist fan system of appropriate spray capacity as well as permissible duration of spraying to avoid exceeding a chosen humidity level.

In this study, experimental measurements are compared to CFD simulation of the experiment done in Ansys FLUENT.

\section{Background on Mist Cooling}

Standards applicable to worker safety such as ISO 7243 and ISO 7933 characterize the heat stress and require increasingly longer rest breaks or cessation of work entirely at increasing levels of thermal stress (International Organization for Standardization, 1989), (International Organization for Standardization, 1994). Performance and productivity generally decrease at effective temperature over $30^{\circ} \mathrm{C}$ (Melikov et al, 1994). The risk of heat stroke increases exponentially at high temperatures (Miyatake et al., 2012), thus even a relatively small reduction in temperature could be highly beneficial in hot environments.

In environment temperatures up to $30^{\circ} \mathrm{C}$, the use of forced convection of an isothermal airflow (a fan) can be an efficient way to maintain the heat balance of the human body (NIOSH, 2016). At higher temperatures, spot cooling with jets of cooled air is often used to reduce heat stress when air conditioning of the entire building is difficult. As for the limit at which full air conditioning is seen as wasteful compared to spot cooling, Mirza et al. (2000) recommend use of spot cooling instead of air conditioning of tin roof factory spaces in a hot desert environment when worker density is 6 per $100 \mathrm{~m}^{2}$ or less. Yet, installation of a spot cooling ducting and diffuser system to cover all workstations from a central air conditioner, or using multiple small units can be expensive. Melikov et al. (1994) recommend that spot cooling jet outlets be "as close as possible to the person" to provide energy-efficient cooling. This can make layout impractical where the workers do not remain in a single 
location or if workspaces are often moved for different projects.

Water mists can be used to provide outdoor cooling on hot summer days at a low energy cost. In single-fluid (hydraulic) mist spray systems, water is pressurized and sprayed through nozzles to create fine droplets. Each nozzle commonly sprays on the order of litres per hour. In outdoor applications, the small droplets evaporate quickly enough that it is easy to position the nozzles such that surfaces in the cooled area will not be significantly wetted even in a sub-tropical climate (Yamada et al., 2006). Such sub-tropical climates include the south-eastern United States, much of Japan, Korea and eastern China, and much of the southeast coast of South America including Buenos Aires (Peel et al, 2007). However, if used indoors, care must be taken. An example of a clean room of $40 \mathrm{~m}^{2}$ floor area with about $200 \mathrm{~m}^{3}$ volume in Japan, ventilated at approximately 2 air exchanges per hour, a mist fan at $3.5 \mathrm{~m}$ height spraying 5 20L/h of mist yielded some floor wetting (Miura et al., 2009). Wetting can be a safety hazard due to the chance of slipping, an equipment hazard due to wetting promoting corrosion or short circuits of electrical equipment, and a liability hazard from persons claiming damages (to clothing, personal effects) due to wetting, among other issues.

The latent heat of evaporation of the droplets, which causes the cooling effect, is well over 100 times the electricity consumption of the high-pressure pump used here to create the mist spray. The major drawback is that evaporation also increases humidity. Further, the limit of the temperature reduction is to the wet bulb temperature. In outdoor and semi-enclosed spaces such as shopping arcades and stadiums, the natural ventilation of fresh air can help prevent the misted space from becoming saturated with water vapour. However, if a mist nozzle is used indoors, a small space could quickly reach $100 \%$ humidity if even a single spray nozzle is used constantly, unless the air exchange rate was high enough to compensate.

Water mist droplets in non-saturated air evaporate, exchanging latent heat for sensible heat from the air. The droplet surface reaches a surface temperature within $+/$ $0.5^{\circ} \mathrm{C}$ of the wet bulb temperature within about 1 microsecond of formation in typical atmospheric conditions (Pruppacher and Klett, 1997). Further, their small mass allows the entire droplet temperature to reach the wet bulb temperature while the effect of air resistance decelerates the droplets to near-zero velocity relative to surrounding air within tens of microseconds. These nearly instantaneous temperature and speed effects can be calculated iteratively as outlined in the work of Chaker et al. (2002) and Holterman (2003). Thus, mist droplets can be assumed as being at near wet bulb temperature and relative air velocity of zero.

The speed of evaporation of a droplet in still air is calculated by assuming that water vapour is an ideal gas, which evaporates at a rate proportional to the difference in its density between the droplet surface and the environment air. The droplet surface is a saturated state at the wet bulb temperature of the environment, such that the change in droplet radius, $r$ over time can be approximated as,

$$
r \frac{d r}{d t}=\frac{D M_{w}}{R \rho_{w}}\left(\frac{e_{o}}{T_{o}}-\frac{e_{s a t}}{T_{a}}\right)
$$

where $D$ is the diffusivity of water vapour in air, $M_{\mathrm{w}}$ is the molecular weight of water, $R$ is the ideal gas constant, $\rho_{\mathrm{w}}$ is the density of water, $e_{0}$ is the vapour pressure of the environment, $e_{\text {sat }}$ is the saturation vapour pressure, $T_{\mathrm{o}}$ is the dry bulb temperature of the environment and $T_{\mathrm{a}}$ is the saturated air temperature. This can also be expressed as,

$$
r \frac{d r}{d t}=\frac{k \Delta T_{w b}}{L \rho_{w}}
$$

where $\Delta T_{\mathrm{wb}}$ is the wet bulb depression, $k$ is the thermal conductivity of moist air, $L$ is the latent heat of evaporation of water, and $\rho_{\mathrm{w}}$ is the density of water. This can be integrated over time to find the approximate time to complete evaporation, $t_{\mathrm{ev}}$ for a single droplet. Taking approximate values for properties of air and water at $25^{\circ} \mathrm{C}$, $L=2250 \mathrm{~kJ} / \mathrm{kg}, \quad \rho_{\mathrm{w}}=1000 \mathrm{~kg} / \mathrm{m}^{3}, \quad k=0.025 \mathrm{~J} / \mathrm{m}-\mathrm{s}-\mathrm{K} \quad$ and expressing drop size as diameter $d$ in units of microns rather than meters, the approximate time for evaporation is,

$$
t_{e v}=\frac{d^{2}}{80 \Delta T_{w b}}
$$

with wet bulb depression in units of Kelvin. Thus, for a 20 micron diameter droplet on a typical hot day in Japan $\left(35^{\circ} \mathrm{C}, 45 \% \mathrm{RH}, \Delta T_{\mathrm{wb}}=10 \mathrm{~K}\right)$ the time to complete evaporation is about $0.5 \mathrm{~s}$, while a 40 micron droplet would be about 2 seconds. However, this calculation assumes a single droplet in unchanging air conditions. As a mist cloud evaporates, $\Delta T_{\mathrm{wb}}$ becomes smaller, reducing evaporation speed in inverse proportion to the change. Still, if the mist is carried by air currents or forced ventilation for a few seconds before reaching any wall or ground surface, there should still be little or no wetting or pooling of water.

As nearly all mist droplets completely evaporate within a few seconds, when examining ventilation of the space on the time scale of hours, mist spray can be assumed as an instantaneous source of water vapour with the same mass flow, $F$, as the mist spray rate. The transient mass flow balance of a ventilated room, assuming the water vapour is uniformly mixed through the air, is

$$
M \frac{d Y}{d t}=F+Q Y_{o}-Q Y
$$

where $Q$ is the constant ventilation mass flow rate into a room containing an unchanging mass of air $M$, where the mass fraction of water vapour of inside air is $Y$, and for outside air is $Y_{\mathrm{o}}$. Air density is assumed constant, as differences between indoor and outdoor air density can generally be ignored for moderate climates (ASHRAE, 2013).

In the case of constant-rate ventilation, the mass fraction of water vapour in the room reaching a steady state at $Y_{\mathrm{ss}}$ with continuous misting would be,

$$
Y_{s S}=\frac{F}{E M}+Y_{o}
$$

where $E$ is the room air exchange rate, $E=Q / M$ (here in terms of mass flow rather than volume flow). This 
assumes that $Q$ is sufficient to prevent $Y_{\text {ss }}$ from reaching the saturated state, which would stop the mist evaporation.

The water vapour mass fraction at any time for constantrate ventilation and mist spraying from an initial condition with water vapour fraction $Y_{\mathrm{i}}$, assuming the uniform mixing and no change in air density is,

$$
Y_{S S}=\frac{F}{E M}+Y_{o}-\left[\frac{F}{E M}+\left(Y_{o}-Y_{i}\right)\right] e^{-E t}
$$

where $t$ is elapsed time in hours. The inverse of the air exchange rate is the time constant of the ventilation equation (ASHRAE, 2013) with the asymptotic limit as Eq. (4). Some deviation from the equations is expected in experiment and in CFD simulation for reasons including; the mist spray slightly changes the temperature and density of the indoor air, the water vapour is not perfectly mixed throughout the indoor space, some larger mist droplets may settle on surfaces and not entirely evaporate, and the ventilation rate itself and mass of moist air in the room is neither constant nor perfectly balanced.

As with traditional cooling towers (which are a form of evaporative cooling) mist cooling systems must be employed with strict maintenance and cleaning protocols, in accordance with ASHRAE Guideline 12 (ASHRAE, 2015) to eliminate the risk of legionella contamination which can lead to deadly pneumonia outbreaks. The system here uses 4 methods to reduce the risk of legionella contamination;

1. Use of chlorinated tap water (all tap water in Japan is chlorinated to at least $0.1 \mathrm{mg} / \mathrm{L}$ )

2. Purge of the misting system and pumps every night, and more strict purge and cleaning at the end and beginning of each cooling season.

\section{Regular changing of filters.}

4. Hot water purges of the system. Temperatures of $60^{\circ} \mathrm{C}$ or higher will destroy legionella bacteria. (WHO, 2007)

\section{Method}

In the experiment, the cooling and humidification effect of a single large mist fan were measured. A circular header with 32 spray nozzles was mounted on the circumference of the fan outlet. The fan was mounted on a platform with the fan axis at $2.5 \mathrm{~m}$ height as shown in Figure 1. This keeps the immediate downstream of the spray nozzles and high air speed (above $10 \mathrm{~m} / \mathrm{s}$ ) at the fan outlet over the heads of workers and most equipment. The mist stream then tends to diffuse and sink toward the floor. The air speed profile of the fan was measured along the centreline (see Figure 2) at $1.2 \mathrm{~m}$ height at $5 \mathrm{~m}$ intervals. The fan was fixed, and air speed measurements taken with a hot-wire anemometer. The values shown in Figure 2 are the $\mathrm{max} / \mathrm{min}$ values. At distance of $10 \mathrm{~m}$ and greater from the fan, the air speed is usually lower than the maximum target velocity of $2.2 \mathrm{~m} / \mathrm{s}$ as recommended for comfortable spot cooling by Melikov et al. (1994).

The fan can oscillate over a $45^{\circ}$ angle with a 50 second period. The fan can also be tilted up and down. In these experiments, the fan was either set level with horizontal as $0^{\circ}$, or with a slight downward tilt at $-4^{\circ}$.
Temperature and humidity sensors were set at 10 locations, 8 within the sprayed area (Points A through $\mathrm{H}$ ). An additional 2 sensors (Point I near the fan inlet and Point $\mathrm{J}$ at $15 \mathrm{~m}$ distance perpendicular to the fan airflow centreline) were placed to monitor the indoor environment beyond the sprayed area, as shown in Figure 2. The sensors were thermistors with capacitive film humidity sensors with built-in data loggers. Response time $(90 \%)$ in still air is 7 minutes, though they can be expected to respond faster due to the forced convection from the fan. The measurement error of these sensors is rated as $+/-0.5^{\circ} \mathrm{C}$ and $+/-5 \% \mathrm{RH}$. These were set to log at 20 -second intervals and referred to from here on as the "slow-response sensors".

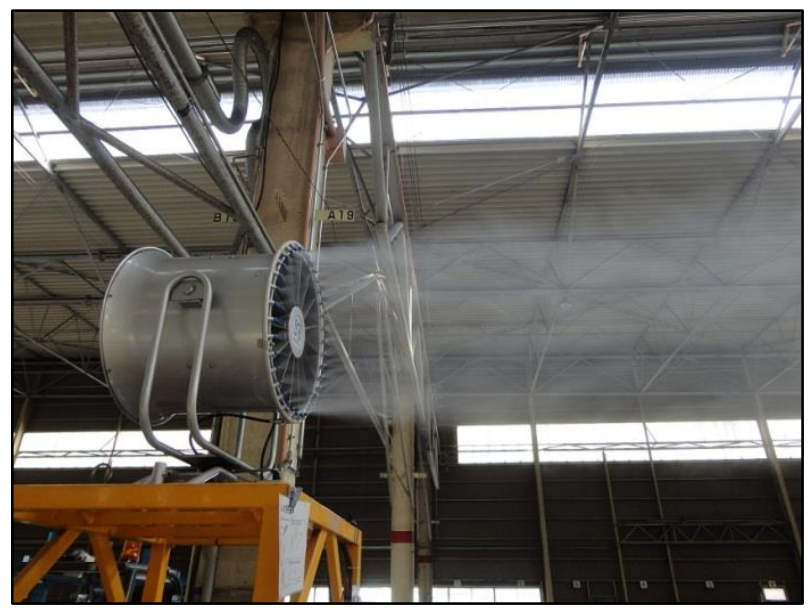

Figure 1. Photo of mist fan (Fan diameter is $60 \mathrm{~cm}$ )

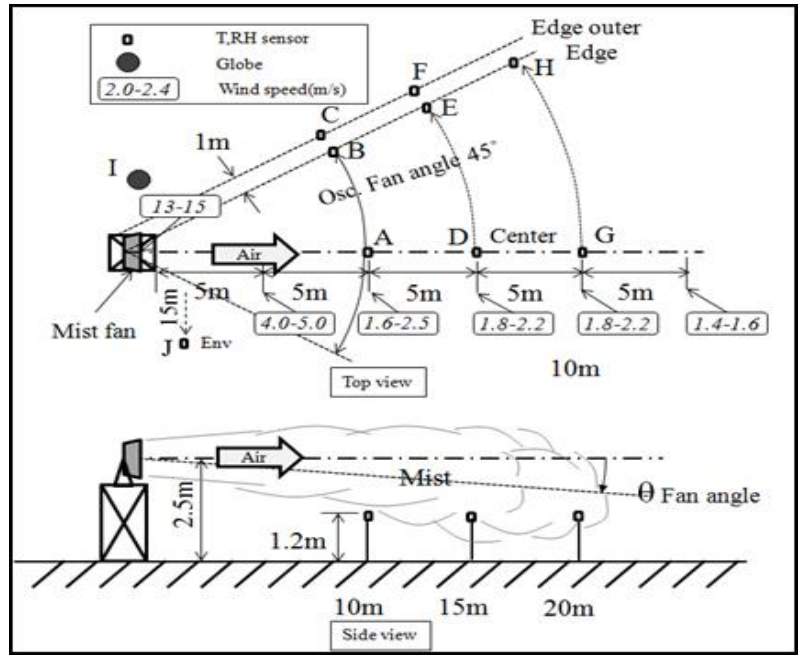

Figure 2. Layout of experiment and sensors

T-type thermocouples made from $0.4 \mathrm{~mm}$ single-core wire with solder beads averaging $1.1 \mathrm{~mm}$ diameter as measured by micrometre were also mounted at each location, connected to an electronic data logger set to record at 1second intervals. From here on these are referred to as the "fast-response sensors". They are rated as $+/-0.5^{\circ} \mathrm{C}$ accuracy, but about 30 of these thermocouple sensors were calibrated in a uniform environment at $20^{\circ} \mathrm{C}$ and only sensors within $+/-0.2^{\circ} \mathrm{C}$ were kept for this experiment. In order to allow the mist to quickly affect them, they were not shielded as is typically recommended to prevent influence of radiant temperature. 
The thermocouple response time is likely shorter during the periods of forced convection as the blown air and mist from the fan is affecting the sensor. An empirical relation for average Nusselt number, $\mathrm{Nu}$ for flow over a constant surface temperature sphere was developed by Whitaker (1972),

$$
N u=2+\left[0.4 \operatorname{Re}^{1 / 2}+0.06 \operatorname{Re}^{2 / 3}\right] \operatorname{Pr}^{0.4}\left(\frac{\mu}{\mu_{w}}\right)^{1 / 4}
$$

where,

$$
N u=\frac{h D}{k}
$$

and $h$ is the surface heat transfer coefficient, $D$ is taken as the thermocouple bead diameter, $k$ is the thermal conductivity of air, $R e$ is the Reynolds number, $\operatorname{Pr}$ is the Prandtl number, $\mu$ is the dynamic viscosity of the fluid at the stream temperature, and $\mu_{\mathrm{w}}$ is the dynamic viscosity of the fluid at the sphere surface temperature. The equation is valid for $0.71<\operatorname{Pr}<380$ and $3.5<R e<$ $7.6 \times 10^{4}$. If the thermocouple bead is a sphere of $1.1 \mathrm{~mm}$ diameter (the average size used in experiment), for an airspeed of $0.2 \mathrm{~m} / \mathrm{s}$ at the low end of the valid Reynolds number range, the Nusselt number is about 3.6, yielding a heat transfer coefficient of $85 \mathrm{~W} / \mathrm{m}^{2} \mathrm{~K}$. This yields a Biot number of 0.003 , indicating that the bead temperature change can be treated as a lumped capacitance model, in which the time constant $\tau$ for temperature change is determined by,

$$
\tau=\frac{\rho C V}{h A}
$$

where $\rho$ is the density of the thermocouple bead, $C$ is its heat capacity, $V$ is the volume, and $A$ is its surface area. This yields a time constant of 3.0 seconds. If the air speed is $2 \mathrm{~m} / \mathrm{s}$, as is the average at most measurement points in the experiment when affected by the fan, the time constant is $1.5 \mathrm{~s}$.

The response time of the thermocouples under natural convection was confirmed by subjecting them to a large step temperature change as outlined in ASHRAE Standard 41.1 (2001). The thermocouples were taken from a room temperature environment at about $20^{\circ} \mathrm{C}$ and moved into a freezer at about $-15^{\circ} \mathrm{C}$ while recording readings at $1 \mathrm{~s}$ intervals. The average time for a $63 \%$ change in temperature reading ranged from 3 to 6 seconds.

\section{Procedure}

The experiment site was a factory warehouse with floor space of about $40,000 \mathrm{~m}^{2}$, air volume of over $500,000 \mathrm{~m}^{3}$ (dimensions are approximately 250m X 150m X 14m) and no internal walls dividing the space. Walls and roof were non-insulated corrugated steel. Much of the space is storage, with some workstations with hand tools or small machine tools. Forklifts and large cargo vehicles regularly enter the space. Doors for vehicles and windows are in all four walls, allowing cross flow natural ventilation. The large volume and many open doors make the factory similar to an outdoor or semi-enclosed space, but with less worry of wind that might scatter the mist away from the intended cooling area. The oscillation of the fan aids circulation of the air, preventing a local build up of humid air in the targeted space. Even if the warehouse had no ventilation, it is expected that the humidification effect of the mist averaged across the building would not approach saturation even after several hours of continuous use.

The system was already being used during work shifts, with word-of-mouth of positive reception by employees, but experiments and measurement were not allowed during normal work hours. The trials were done on a weekend between the hours of 10:00AM and 4:00PM. There was no work activity within the test area, and minimal activity in the entire warehouse as it was part of a 3-day holiday weekend (which made it possible to get permission to conduct the experiment in the first place). Several large vehicle doors, which accommodate trailer trucks, and are usually left open during working hours, were open during the trials. The initial air temperature in the factory ranged over $26-29^{\circ} \mathrm{C}$ and humidity from 30 $45 \%$ during the test periods. A 30-minute testing cycle as shown in Figure 3 was repeated for 16 trials. The short spans of misting were intended to test the "recovery time" after stopping the mist. Further, the changes in outdoor air (and thus indoor environment) temperature and humidity over the span of the day could easily become a confounding factor when determining the effect of the mist on air conditions. If a mist spray trial were run continuously from 10:00AM to 1:00PM, while the outdoor and overall indoor temperature slowly rose by $3 \mathrm{~K}$, given that the mists used here typically yield a temperature decrease on the order of $1-2 \mathrm{~K}$, it would be difficult to isolate the mist cooling effect over the entire period. The effect of the fan only and fan with mist were measured in each trial, with the expectation that fan only periods would serve as a control case, yielding no significant change in temperature or humidity. The fan was set to oscillate for 12 trials, and fixed for 4 trials. The

\begin{tabular}{|c|c|c|c|c|c|c|c|}
\hline \multicolumn{8}{|c|}{ Move sensors, change fan settings } \\
\hline $\begin{array}{l}\text { Stop } \\
\text { (1) }\end{array}$ & $\begin{array}{l}\text { Fan } \\
\text { only }\end{array}$ & Stop & Fan and mist & Stop & $\begin{array}{l}\text { Stop } \\
\text { (2) }\end{array}$ & $\begin{array}{l}\text { Fan } \\
\text { only }\end{array}$ & \\
\hline 0 & 5 & 10 & 15 & 25 & 30 & 35 & 40 \\
\hline \multicolumn{8}{|c|}{ Elapsed time (min) } \\
\hline
\end{tabular}
fan was set at a $0^{\circ}$ tilt for 12 trials and at a $-4^{\circ}$ (downward) tilt for 4 trials.

Figure 3. Experiment procedure schedule

\section{Simulation}

A CFD model of a portion of the factory with one mist fan unit was created in Ansys FLUENT 14.0 to determine the actual temperature drops that are difficult to measure, to help visualize the cooling effects across a large room volume and to test the effect of ventilation (as the ventilation rate of the experiment space was unknown). To reduce computation time, instead of a model of the entire factory space, a $40 \mathrm{~m} \times 80 \mathrm{~m} \times 14 \mathrm{~m}$ room (as shown in Figure 4) with a mist fan of the same specifications as the experiment was modelled. The model used closed, adiabatic boundaries for all walls and ceiling, with the exception of two vehicle doors and 2 long windows for ventilation near the ceiling. These were positioned on opposite sides of the room, similar to the experiment site. 
Ventilation was set as a uniform velocity flow from both the window and door on one side, with the opposite side set as a free outlet condition.

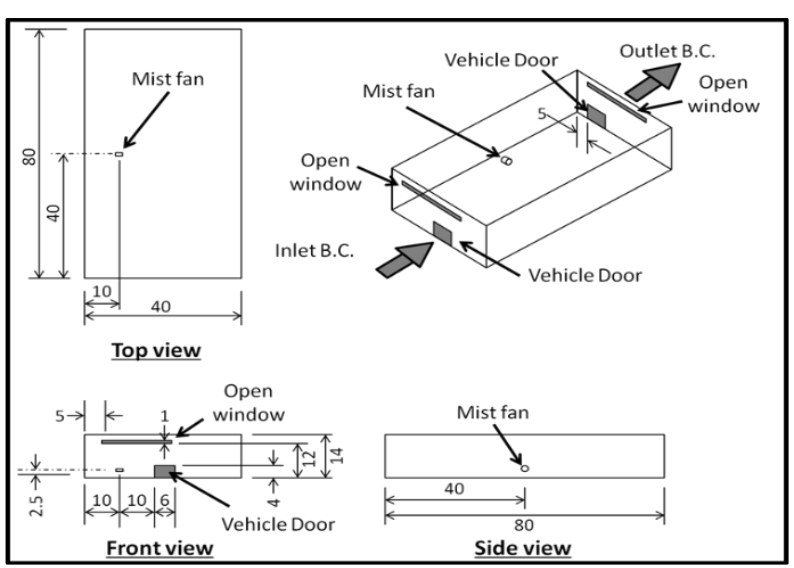

Figure 4. Simulation dimensions and boundary conditions (Units in meters)

The mesh is tetrahedral, comprising over 245,000 elements across the entire volume. In the immediate radius $(2 \mathrm{~m})$ around the fan, the maximum element length was set to $0.2 \mathrm{~m}$. Within a $16 \mathrm{~m}$-diameter sphere covering the immediate downwind region from the fan, the element size was set to $0.5 \mathrm{~m}$. Elements gradually become larger to a maximum size of $2 \mathrm{~m}$ at the wall boundaries. The time step was set as 0.5 seconds. The fan was modelled as a solid wall tube with pressure boundaries at each end to generate the same air flow as the actual fan. The mist spray was modelled as a hollow-cone water droplet injection with 12 streams with the same total flow as the 36 nozzles. The fan and nozzles spray assembly was set in a cylinder with a sliding mesh boundary with the surrounding air. This cylinder was set to oscillate at the same rate as the fan in experiment with a User Defined Function (UDF).

Temperature, relative humidity, and air speed were recorded with virtual sensors at the same relative position to the fan as in the experiment. Average temperature and average water vapour mass fraction of the entire space were recorded at each time step.

The simulation was run with an initial temperature of $35^{\circ} \mathrm{C}$ and initial humidity of $45 \% \mathrm{RH}$, typical of a hot summer day in Japan, such that the mass fraction of water vapour is $0.016 \mathrm{~kg} / \mathrm{kg}$ of moist air. The mist spray settings are set with the same flow rate $\left(0.51 \mathrm{~m}^{3} / \mathrm{h}\right)$ and average droplet diameter of a fan in the actual system. The droplet diameters were distributed over 10 bins to include the influence of larger droplets up to a maximum of 80 microns, to match the values of the droplet diameter distribution as measured by the nozzle manufacturer. The air exchange rate is set at 1 by setting the inlet door and windows to allow a stream of moist air at the initial condition at a constant $0.31 \mathrm{~m} / \mathrm{s}$, this roughly matches the "worst case" (slowest) air speed on site in the experiment days. The fan was set to oscillate with a 50 second period throughout the simulation, with mist spray starting at elapsed time of 1 second, to avoid compounding any instability of simultaneous fan and mist activation. The time step was $0.5 \mathrm{~s}$ throughout the simulation. The mist sprays for 5 minutes, stops for 5 minutes, sprays for 5 more minutes, then stops. To test the effect of increased air changes, the air change is increased to 4 at elapsed time of 7.5 minutes and continued at 4 until the end of the run. The entire simulation was repeated with the same mist and fan conditions, but with the initial air condition set at $27^{\circ} \mathrm{C}$ and $40 \% \mathrm{RH}$ as a water vapour mass fraction of 0.009 $\mathrm{kg} / \mathrm{kg}$ moist air, similar to the conditions during the experiments.

\section{Results}

The mist caused measurable temperature drops and humidity increases. As expected, humidity and temperature did not significantly change during the fanonly periods. Examples of this sensor data are shown in Figure 5, which shows the measurements along the fan oscillation centreline (points A,D,G), with measurements of room environment not immediately affected by the mist at the fan inlet (point I) and well outside the mist area (point $\mathrm{J}$ ) included. The flags along the $\mathrm{x}$-axis show fan only operation " $\mathrm{F}$ ", and misting fan operation " $\mathrm{M}$ ", with the break between the 2 modes as blank space. Temperature drops by up to about $1.0-1.5 \mathrm{~K}$ along the fan centreline (points $A, D, G$ ) while humidity only rises by about $5 \%$. The cooling effect was slightly greater at the edge (points B,E,H). This is likely due to the oscillation pattern of the fan. Near each edge the fan and mist cloud lingers longer as the fan oscillation slows and reverses direction. At the centreline the fan and mist cloud passes by more quickly. However, the centreline experiences two passes of the fan and mist per cycle, while each edge experiences only one pass. The slow response of the sensors is also a factor.

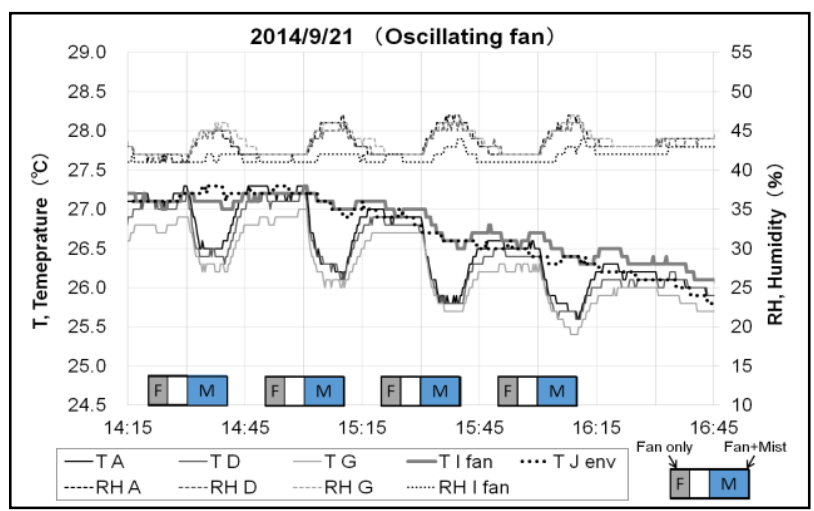

Figure 5. Example of temperature and humidity measurement by slow-response sensors

The quick-response sensors only measured temperature. They clearly show the temperature dropping and recovering to nearly the initial temperature as the fan oscillates, as in Figure 6. This fast-response data was used to calculate an average temperature drop $\Delta T_{\text {avg }}$ over each misting period and the average maximum temperature drop $\Delta T_{\text {peak. }}$ as shown in Table 1 . According to ASHRAE 55 (2013), time averaging of air temperature for comfort calculations is to be done for "periods of not less than 3 minutes and not more than 15 minutes", thus the value $\Delta T_{\text {avg }}$ would be used if trying to evaluate the cooling effect 
in the standard thermal comfort models. However, in our previous research (Farnham et al., 2015) it was found that skin surface temperatures can drop on the order of $1-2 \mathrm{~K}$ within less than 10 seconds of exposure to mist, with similar rapid change in thermal sensation votes, thus $\Delta T_{\text {peak }}$ may be more valuable in estimating the thermal comfort vote of people exposed to an oscillating mist fan. Note that for the fixed fan case, the temperature changes at points not along the centreline $(\mathrm{B}, \mathrm{C}, \mathrm{E}, \mathrm{F}, \mathrm{H})$ registered small positive and negative values. As the fixed mist was not directly affecting these points, they are likely random changes.

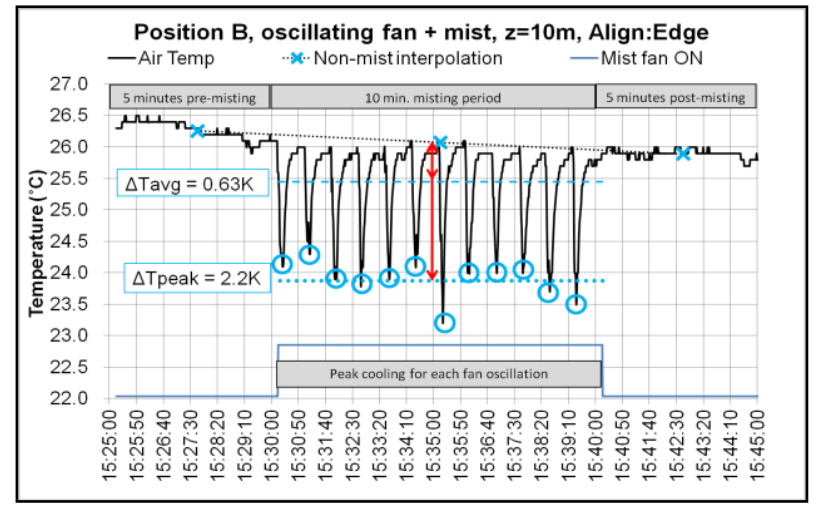

Figure 6. Temperature drops using fast-response sensors during oscillating fan misting

Table 1: Temperature change (average and peak) during misting periods.

\begin{tabular}{|c|c|c|c|}
\hline \multirow{2}{*}{ Point } & Fixed & \multicolumn{2}{|c|}{ Oscillating } \\
\cline { 2 - 4 } & $\Delta T_{\mathrm{avg}}(\mathrm{K})$ & $\Delta T_{\mathrm{avg}}(\mathrm{K})$ & $\Delta T_{\text {peak }}(\mathrm{K})$ \\
\hline A & 2.7 & 0.5 & 2.5 \\
\hline B & -0.1 & 0.5 & 2.5 \\
\hline C & -0.4 & 0.1 & 1.4 \\
\hline D & 1.4 & 0.3 & 1.4 \\
\hline E & -0.6 & 0.4 & 1.7 \\
\hline F & 0.0 & 0.2 & 1.4 \\
\hline G & 1.2 & 0.3 & 1.1 \\
\hline H & -0.1 & 0.4 & 1.5 \\
\hline
\end{tabular}

The example data in Figure 6 includes a diagram of the calculation technique. The time-averaged temperature of the 5-minute periods before and after misting is stopped are calculated. The average of these two is treated as an interpolation that indicates what the temperature might have been in the room if no mist cooling had taken place. The difference between this "no mist" interpolation and the average temperatures (simple time average and average of peaks) during misting are taken as the temperature drop due to the mist. When oscillating, the relatively long time when no mist is passing over the sensors is included in $\Delta T_{\text {avg }}$, yielding a small timeaveraged change over the misting period. The larger $\Delta T_{\text {peak }}$ better shows the change when the mist effect is reaching the sensors during each oscillation cycle. The maximum temperature drop in each 50 second oscillation (or 25 seconds when measured along the centreline, as the mist passes twice) is taken, and all these maxima are averaged to yield the average of the "peak" temperature drops. When the fan is fixed, there is almost no change in conditions beyond the centreline points. There is also no periodic cycling of the temperature, and thus no need for the $\Delta T_{\text {peak }}$ calculation. Recent thinking on thermal alliesthesia (Parkinson and de Dear, 2015) has hoped to exploit the fact that thermal pleasure can be associated with thermal transients. The effect of repeated large, quick temperature drops from the oscillation with slower recovery to original ambient may have value in creating a pleasant thermal environment.

To test the convergence of the model, the average mass fraction of water vapour in the simulated room was compared to the theoretical increase as calculated by Eq. (5) and shown in Figure 7. The values differ by less than $4 \%$ throughout the simulated period, with the largest difference at the end of the period.

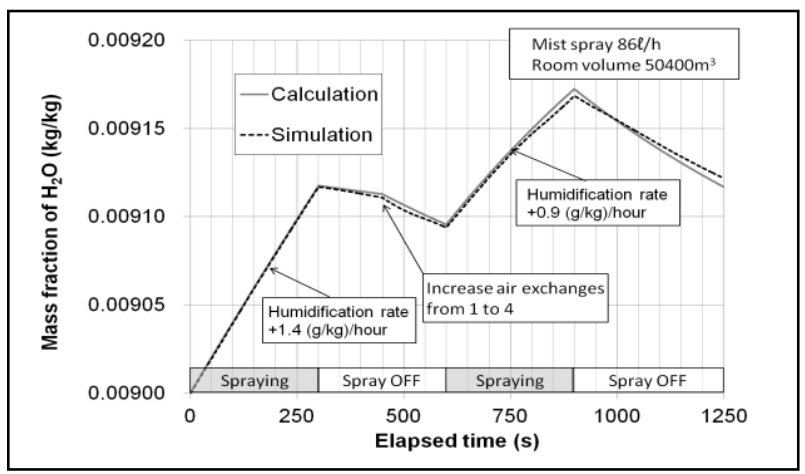

Figure 7. Average vapour mass fraction (simulation vs. theoretical calculation)

The temperature changes in the simulation tend to be greater than those in experiment at the same location. An example is shown in Figure 8. Note that because the simulation initial conditions were set uniformly throughout the space, while the experimental measurements varied over time and space, the temperatures measured in experiment and the temperatures according to simulation do not align well in a graph. To allow easier visual comparison of the temperature change, they are plotted on different vertical axes. The period of the temperature changes matches experiment well, but the simulated values tend to have larger changes. This may be due to the experiment sensor time lag not allowing them to register the full temperature drop before the mist has already passed. Virtual sensors in simulation effectively have no time lag, thus would represent the "actual" temperature changes in the simulation. Further, the flow pattern of the mist (turbulence, eddies, swirl, etc.) in the simulation could not be confirmed to match that in reality. If the mist in the simulation is more dense than in reality, such as due to slower radial diffusion of the mist cloud, that would also yield greater temperature drops at the virtual sensors.

To test this time lag influence, a time lag is applied to the simulation temperature output. At each time step $\Delta t$, the simulation temperature of the following time step $T_{\mathrm{i}+1 \text {,sim }}$ is taken as the "actual" temperature, and the difference between this and the current time step temperature $T_{\mathrm{i}}$ is taken as the step change, then a time constant $\tau$ is applied to find the apparent temperature at the next time step $T_{\mathrm{i}+1}$ as per the chosen time constant in Eq. 9, 


$$
T_{i+1}=T_{i}+\left(T_{i+1, \operatorname{sim}}-T_{i}\right)\left(1-e^{-\Delta t / \tau}\right)
$$

Time constants of $1 \mathrm{~s}$ and $2 \mathrm{~s}$ are applied to examples of simulation output. The difference between the calculated temperature and the initial temperature is taken as the temperature change (with negative as a lower temperature) and shown in Figure 9 along with the temperature changes for original simulation data and experimental data. The experimental temperature change falls between the $1 \mathrm{~s}$ and $2 \mathrm{~s}$ temperature lags for most of the $300 \mathrm{~s}$ in which the calculation was performed, indicating that the assumption that temperature drop due to mist may be larger than that registered by the sensors in experiment, due to the sensors time lag, may have merit.

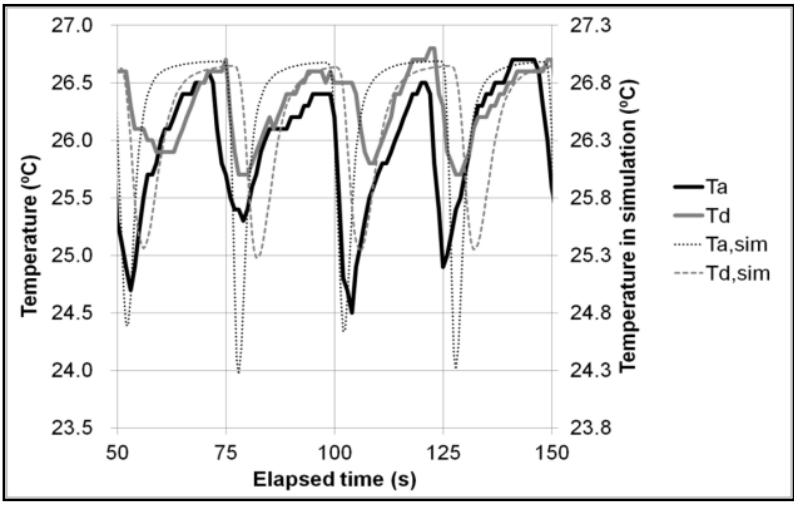

Figure 8. Temperature drops in experiment compared to simulation (Positions A and D, centreline)

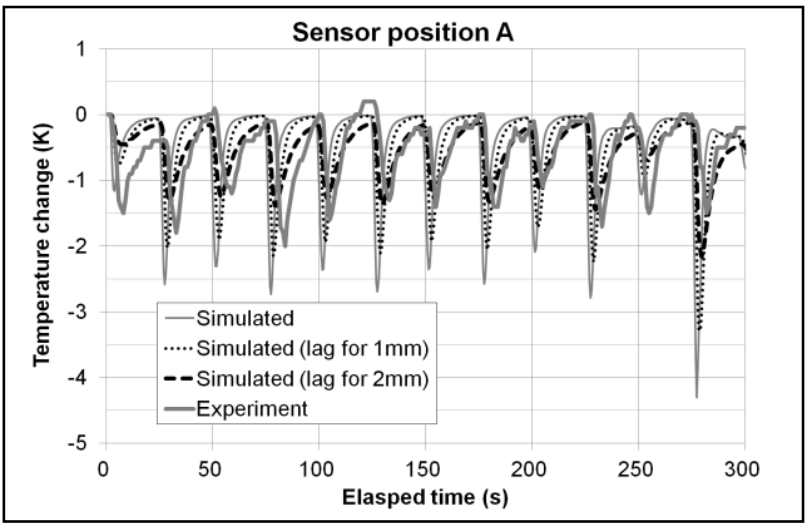

Figure 9. Simulation results for temperature drops, simulated sensor time lag, and experiment

Simulation results for relative humidity at each virtual sensor indicated a similar trend in which the experimental humidity sensors may not register the full change in humidity. This is expected as the response time of the sensors ( 7 minutes in still air) is much slower than the oscillation period (50 seconds). Simulated relative humidity for positions A, D and G (10m, 15m and 20m from the fan, along the centreline) are shown in Figure 10. Instantaneous peaks are about 5-10\% higher than the initial $41 \%$ humidity level. Measured humidity increase in experiment rose only to about $5 \%$ above initial values. Yet, both experiment and simulation show that in the case of intermittent spraying, there is little chance that the humidity level will increase to saturation, nor even $70 \% \mathrm{RH}$, which is used as the stop condition for the automatic control system. The calculations considering air exchanges above showed that there is little chance of air saturation even after several hours of continuous spraying in this large space with this system.

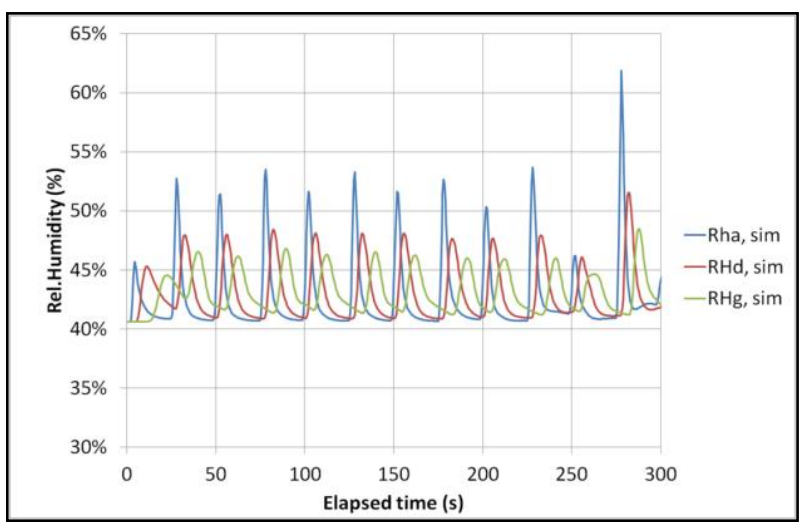

Figure 10. Simulation results for humidity rises along the centreline

Cross-sections of temperature at elapsed misting time of 299 seconds (1 second before misting is stopped), perpendicular to the fan airflow direction at the centre of the oscillation period are shown in Figure 11 (with initial conditions at $27^{\circ} \mathrm{C}$ ) where $z$ indicates the distance from the fan. A cross section along the $y$-axis, parallel to centre of the fan oscillation is also included. The simulation at $35^{\circ} \mathrm{C}$ initial condition yielded nearly identical temperature changes. Note that the " $z=30 \mathrm{~m}$ " cross-section is actually that at $29.9 \mathrm{~m}$ from the fan, as the wall is at $30 \mathrm{~m}$. The cooled air appears to reach the far wall at $\mathrm{z}=30 \mathrm{~m}$, and circulates back toward the fan along the outer edges of the space. The cross-sections shown are to scale, with the height as $14 \mathrm{~m}$. The cooled air reaches well over half the height to the ceiling and appeared to be well-mixed across the lower half of the space in both cases.

\section{Conclusions}

The oscillating mist fan used here can yield peak temperature drops up to about $2.5 \mathrm{~K}$ at the mist passes over a $45^{\circ}$ angle at distances $10-20 \mathrm{~m}$ from the fan. The timeaveraged temperature drops ranged from $0.1-0.5 \mathrm{~K}$. Unshielded thermocouple measurements showed that the temperature tended to recover to near the initial value by the time the mist returned for another pass. The mass flow of water mist sprayed is relatively small compared to the large volume of the space, thus continuous spraying for several hours is possible with no concern of saturating the air with water vapour, even at very low air exchange rates.

CFD simulation shows that the transient temperature drops may be greater than measured in experiment. The response time of the sensors not allowing them to register the full effect as the mist passes is a likely factor. The simulation also shows that the cooled air is mixed over much more of the space than just the oscillation angle of the fan, preventing a local build up of moist air.

However, it is also possible that the mist droplets may not have fully evaporated before reaching some of the sensors (especially the sensors at $10 \mathrm{~m}$ distance, though visual observation seems to show that droplets have fully evaporated at about $15 \mathrm{~m}$ distance) and thus the full 
cooling effect may not have been evoked at 10m, which would affect the actual temperature drop timing and the sensor response timing. Further analysis of this timing and its effect on air temperature will be a subject of future study.

It is expected the misting fan can increase thermal comfort for factory workers on hot summer days with no worry of large increase in humidity levels. The role of thermal alliesthesia could make the repeated temperature drops with slow recovery more pleasant than the time-averaged temperature drop would indicate. In continuing research, a statistical analysis of the results and a sensitivity analysis for the simulation (different mesh size, time step) is being done, while the comfort and physiological response of humans to the mist fan is being investigated.

\section{Acknowledgement}

The research was funded by general research budget of Osaka City University and by funds from H. Ikeuchi \& Co. Ltd. as arranged by a co-author, Mr. Takeo Mizuno. Mr. Mizuno arranged access to the warehouse site and provided instruction on safe and typical operation of the mist fan unit as it is used in practice. He was not involved in data collection, analysis, nor interpretation of the experiment data, nor the writing of this report with the exception of the system description and background on use of the system at the warehouse.

\section{References}

ASHRAE (2013). ASHRAE Handbook - Fundamentals 16 Ventilation and Infiltration.

ASHRAE (2013). ASHRAE Handbook - Fundamentals 36 Measurements and Instruments "Sources of Thermometer Errors".

ASHRAE (2001). Standard Method for Temperature Measurement 41.1-1966(RA2001). [Accessed at ASHRAE website, 2016].

ASHRAE (2013). Thermal Environmental Conditions for Human Occupancy (55-2013).

ASHRAE (2000). Minimizing the Risk of Legionellosis Associated with Building Water Systems (Guideline 12-2000).

Chaker, M., Meher-Homji, C. and Mee III, T. (2002). Inlet Fogging of Gas Turbine Engines - Part A, Proc. Of ASME Turbo Expo, Amsterdam, Report \#2002-GT30562 .

Farnham, C., Emura K., and Mizuno, T. (2015). Evaluation of cooling effects: outdoor water mist fan. Building Research \& Information 43(3), 334-345.

Holterman, H. (2003). Kinetics and evaporation of water drops in air. IMAG, (Report 2003-12/Wageningen $U R$ ) Wageningen, The Netherlands.

International Organization for Standardization (1989). Hot environments -- Estimation of the heat stress on working man, based on the WBGT-index (wet bulb globe temperature) ISO 7243:1989.
International Organization for Standardization (2004). Ergonomics of the Thermal Environment - Analytical Determination and interpretation of heat stress using calculation of the predicted heat strain. ISO 7933:2004.

Melikov, A., Haljaker, L., Arakelian, R. and Fanger, P. (1994). Spot Cooling - Part 1: Human responses to cooling with air jets. ASHRAE Transactions Vol. 100, Part 2, 476-499.

Melikov, A., Haljaker, L., Arakelian, R. and Fanger, P. (1994). Spot Cooling - Part 2: Recommendations for design of spot-cooling systems. ASHRAE Transactions Vol. 100, Part 2, 500-523.

Mirza, A., Al-Taqi, H. and Maheshwari G. (2000). Spot coolers as an alternative to conventional cooling. Proc. World Renewable Energy Congress VI, 2232-2236.

Miura, T., Itatani, T., Kuriki, S., Takuma, M., Suzuki, T. and Kosugi, S. (2009). Experimental study on evaporation cooling effect by sprayed mist in indoor space: Part 1 Outline of experiment and cooling effect by sprayed mist with circulation fan. Architectural Institute of Japan Conference Summaries, Vol. D-2, 561-562. [in Japanese]

Miyatake, N., Sakano, N. and Murakami, S. (2012). The relation between ambulance transports due to heat stroke and air temperature using daily data in Okayama prefecture, Japan. Open Journal of Preventive Medicine Vol.2(1), 112-115.

Parkinson, T. and de Dear, R. (2015). Thermal pleasure in built environments: physiology of alliesthesia. Building Research \& Information 43(3), 288-301.

Peel, M., Finlayson, B., and McMahon, T. (2007). Updated world map of the Köppen-Geiger climate classification. Hydrology and Earth System Science 11, 1633-1644.

Pruppacher H, Klett J. (1997). Microphysics of Clouds and Precipitation. Dordrecht: Kluwer Academic Publishers.

U.S. Department of Health and Human Services, Centers for Disease Control and Prevention, National Institute for Occupational Safety and Health (NIOSH) (2016). NIOSH criteria for a recommended standard: occupational exposure to heat and hot environments. Publication 2016-106.

Whitaker S. (1972). Forced convection heat transfer correlations for flow in pipes, past flat plates, single cylinders, single spheres, and for flow in packed beds and tube bundles. AIChE Journal 18(2), 361-371.

World Health Organization (2007). Legionella and the prevention of legionellosis.

Yamada, H., Okumiya, M., Tsujimoto, M. and Harada, M. (2006). Study on cooling effect with water mist sprayer: Measurement on global loop at the 2005 world exposition. Architectural Institute of Japan Conference Summaries Vol. D-1, 677-678. [in Japanese] 

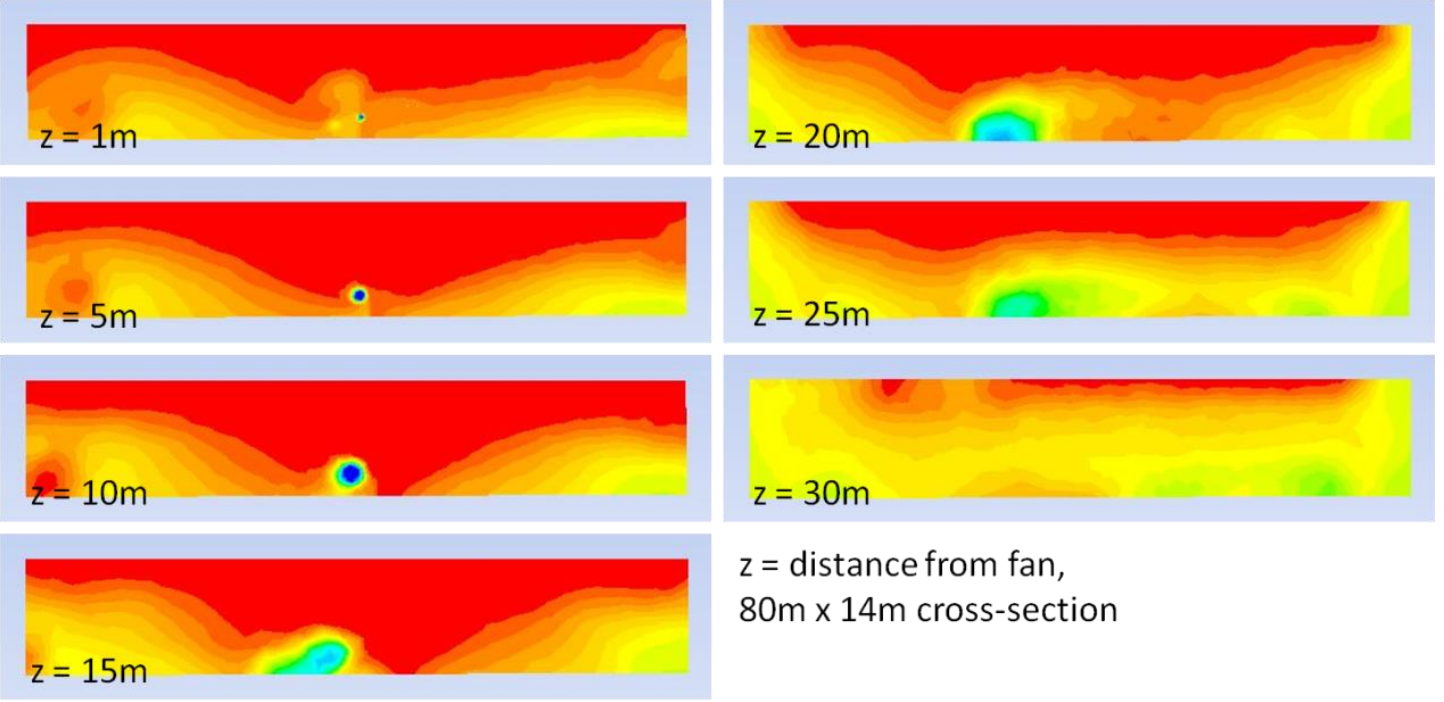

$\mathrm{z}=$ distance from fan,

$80 \mathrm{~m} \times 14 \mathrm{~m}$ cross-section

25.0
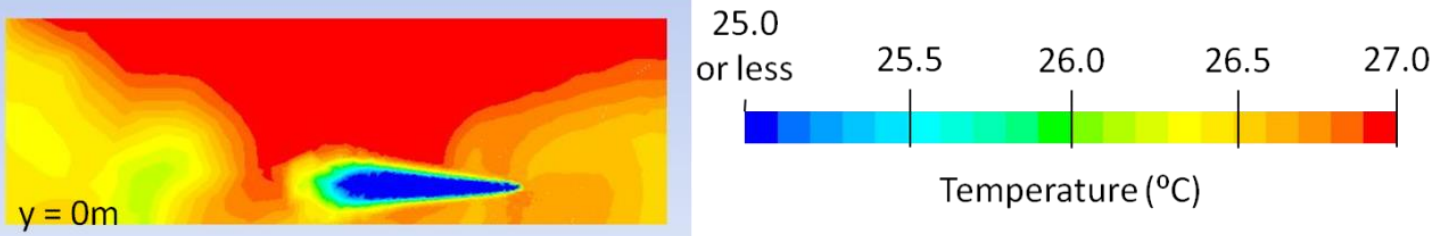

$y=0 m$

Temperature $\left({ }^{\circ} \mathrm{C}\right)$

Figure 11. Cross-sections of temperature at increasing distance from the fan, $z$, and along the fan axis, for a $27^{\circ} \mathrm{C}$ case 